\title{
A Novel Methodological Approach to Estimate the Impact of Natural Hazard-Induced Disasters on Country/Region-Level Economic Growth
}

\author{
Sayanti Mukherjee ${ }^{1,2,3} \cdot$ Makarand Hastak $^{1,3}$
}

Published online: 21 December 2017

(c) The Author(s) 2017. This article is an open access publication

\begin{abstract}
With the increased frequency of extreme weather events and large-scale disasters, extensive societal and economic losses incur every year due to damage of infrastructure and private properties, business disruptions, fatalities, homelessness, and severe health-related issues. In this article, we analyze the economic and disaster data from 1970 through 2010 to investigate the impact of disasters on country/region-level economic growth. We leveraged a random parameter modeling approach to develop the growth-econometrics model that identifies risk factors significantly influencing the country/region-level economic growth in the face of natural hazard-induced disasters, while controlling for country/region- and time-specific unobserved heterogeneities. We found that disaster intensity in terms of fatalities and homelessness, and economic characteristics such as openness to trade and a government's consumption share of purchasing power parity (PPP), are the significant risk factors that randomly vary for different countries/regions. Other significant factors found to be significant include population, real gross domestic product (GDP), and investment share of PPP converted GDP per capita. We also found that flood is the most devastating disaster to affect country/region-level economic growth. This growth-econometrics model will help in the policy and decision making of governments
\end{abstract}

Sayanti Mukherjee

sayanti.purdue@gmail.com; mukhopa0@purdue.edu

1 Lyles School of Civil Engineering, Purdue University, West Lafayette, IN 47907, USA

2 School of Industrial Engineering, Purdue University, West Lafayette, IN 47907, USA

3 Division of Construction Engineering and Management, Purdue University, West Lafayette, IN 47907, USA related to the investment needs for pre- and post-disaster risk mitigation and response planning strategies, to better protect nations and minimize disaster-induced economic impacts.

Keywords Disaster risk reduction - Economic growth · Growth econometrics - Impact of natural hazard-induced disasters - Panel data analysis - Random parameter modeling

\section{Introduction}

Our society and critical infrastructure systems are threatened with ever-increasing risks of climatic change leading to frequent extreme weather events such as coastal flooding due to sea-level rise, droughts and heatwaves owing to increasing global mean temperature, and other hydrometeorological hazards such as hurricanes, tropical cyclones, typhoons, among others (Mukherjee 2017). These climatic change and extreme weather induced hydroclimatological events can cause extensive damage to infrastructure and communities (direct impacts) or might cause unwanted shifts in the end-use demand patterns (indirect impacts) (Mukherjee and Nateghi 2017a, b, c; Nateghi and Mukherjee 2017). Critical infrastructure systems-including energy systems, water systems, transportation, health care, information and communications technology, security, and financial services-underlie the economic prosperity of every society. Thus, ensuring resiliency of these highly complex, interactive, and interdependent systems is of utmost importance, because of the essential services that they provide to our society. Natural catastrophes-such as the Fort McMurray wildfire in Canada (2016), hurricanes Katrina (2005) and Superstorm Sandy (2012) in the United 
States, typhoon Haiyan in the Philippines (2013), the Tohoku earthquake (2011), the Nepal earthquake (2015), and tsunamis in Japan $(2011,2014)$-highlight the extent to which both high-income and low-income countries are vulnerable to natural hazard-induced disasters, facing critical challenges related to adaptation and disaster risk mitigation (Munich RE 2012; Katz 2013; Cadwalladr 2015; NASA 2016; Plyer 2016). These large-scale disasters witnessed thousands of fatalities, injuries, homelessness, infrastructure damages, and business disruptions, leading to extensive economic and societal loss. Comparing several climate models, the NASA (National Aeronautics and Space Administration) Earth Observatory identified a common increasing trend in global temperature rise that will lead to an increase in mean sea level ranging from 0.11 to $0.77 \mathrm{~m}$ by 2100 (Riebeek 2005). Moreover, the warmer sea surface would also lead to increased risk of turbulent tropical storms, coastal flooding, drought, and so on (Riebeek 2005).

In such a scenario, it is customary to believe that natural hazard-induced disasters have significant negative impacts on the short-term economy whereas their effects on the long-term economy is dubious and inconclusive (AlbalaBertrand 1993; Noy and DuPont 2017). There are various arguments considering the long-term and short-term effects of disasters on country-level economic growth (Mukherjee and Hastak 2016). In general, any disaster (depending on its type-flood, storm, earthquake, and so on) destroys immense physical properties and human life that are evidently believed to be factors in influencing any country's economic growth. Such disasters are extremely unfortunate events that extensively impact economically poor and underdeveloped countries because of the lack of adequate disaster preparedness, absence of advanced early warning systems, poor infrastructure conditions, and inadequate community protection. At the same time, these countries get aid from other governments, the World Bank, the United Nations, and several other funding agencies in a post-disaster period to build back their economy better, so that it might create new jobs, develop resilient infrastructures, strengthen communities, and so on. From a long-term perspective, disasters may aid in the economic development of the developing and underdeveloped countries by initiating a flow of funds and resources through post-disaster financing.

Therefore, there is a need to analyze and understand the effect of natural hazards on country-level economic growth so that adequate measures can be taken to minimize the disaster impact by introducing new, or modifying the existing pre- and post-disaster mitigation policies. In this research, we focus only on the direct impacts of disaster events; quantifying the indirect impacts of disasters on the economy is beyond the scope of this research. We leveraged a random parameter modeling approach that is flexible enough to account for all the different types of unobserved heterogeneities, which is one of the major challenges in disaster data analytics. We identified the important risk factors and estimated their causal impacts on country/region-level economic growth.

Section 2 provides a literature review that helps in identifying the gaps in the current body of knowledge related to the relationships between economic growth and natural hazard-induced disaster impacts. Section 3 describes the research methodology including the model construct and the different data types used in this analysis. Section 4 presents a discussion on the analysis results and model inference. Section 5 explains our research limitations, and in Sect. 6 we summarize our findings and recommendations for future research. The outcomes of this research will support the decision-making processes of various stakeholders such as government and nongovernmental agencies in the country-level, pre-disaster planning and disaster risk reduction processes.

\section{Understanding the Nexus of Economic Growth and Natural Hazard-Induced Disaster Impacts}

The impacts of natural hazard-induced disasters have significant macroeconomic consequences. Numerous studies have been conducted to understand the influence of social, political, financial, and policy-related factors on the economic growth of countries. Headey and Hodge (2009) analyzed the effect of population growth on country-level economic growth. Momota (2009) developed a theoretical populationmacroeconomic growth model to study the effects of fertility, child education, and education policies on the future economic growth of developing countries. Tang and Abosedra (2014) conducted a panel data analysis on 24 Middle East and North African countries to analyze the impacts of tourism, energy consumption, and political instability on their economic growth. Qayyum and Haider (2012) extended the neoclassical growth model of Solow-Swan (Dowrick and Rogers 2002) to investigate the effect of institutional quality, that is, governance, financial debt, and foreign aid on the economic growth of low-income countries. Aisen and Veiga (2013) and Jong-A-Pin (2009) investigated the effects of political instability on the economic growth of countries using a panel data analysis approach and found that a higher degree of political instability is associated with a lower growth rate. Although this literature is not exhaustive, it is evident that the study of growth econometrics is an important topic that needs further attention.

Recently there has been a growing interest among economists in studying the effects of natural hazard- 
induced disasters on economic growth (Cavallo et al. 2010; Hochrainer 2009; Noy 2009; Cunado and Ferreira 2011; Kousky 2012; Sadia et al. 2012; Shabnam 2014), the major reason being the inconclusive and contradictory literature in this research area. Some studies have observed that there is a positive influence of such disasters on the economy while others found negative or no effects. Shabnam (2014) found that the death toll from floods has no significant effect on the GDP per capita growth rate, whereas it is significantly influenced by the extent to which people are affected by a disaster. Cunado and Ferreira (2011) also analyzed the impact of floods on the economy of disasteraffected countries using historical data from 3184 large flood events that occurred in 118 countries during 1985-2008. They found that such flood events tend to have a positive influence on the gross domestic product (GDP) of developing countries. Cavallo et al. (2010) conducted studies of both the long-run and short-run impacts of natural hazard-induced disasters on country-level economic growth and concluded that, in both the cases, such impacts indicated that growth is negatively affected in the face of any disaster. Hochrainer (2009) found from a midterm analysis (up to 5 years after the disaster events) that natural hazard-induced disasters on average have negative macroeconomic impacts, the magnitude of the impact being dependent on the size of the shock. Research by Noy (2009) found that following a disaster, developing countries and small economies face a relatively large shock compared to that of developed countries. Countries with a higher rate of literacy, better educational institutions, higher per-capita incomes, larger government size, and higher degrees of openness to trade are found to be more resilient in the face of major disaster impacts (Toya and Skidmore 2007; Noy 2009). Although several studies related to natural hazard-induced disasters and growtheconometrics are emerging, this area of research is still in its nascent stage. In this article, our goal is to provide a basic understanding of the impact of such disasters on economic growth in terms of significant economic and disaster impact indicators.

\section{Methodology}

We leveraged a random parameter modeling approach to estimate the impact of natural hazard-induced disasters on country/region-level economic growth. This modeling approach is an alternative to the fixed effects models conventionally used for the analysis of longitudinal data. Both these models have their pros and cons and the outcomes will vary based on the types of data used. However, comparing these two types of models is outside the scope of this article.
The random parameter (mixed) modeling approach is a comparatively new econometric modeling technique that has been mostly applied to crash data analysis in transportation engineering (Anastasopoulos and Mannering 2009, 2011; Dinu and Veeraragavan 2011; Venkataraman et al. 2013). Besides crash data analysis, this modeling approach has been also applied to other types of research. For example, determining optimal levels of fertilizers in agriculture production (Tumusiime et al. 2011), developing economic models for willingness to pay (Carlsson and Martinsson 2007), developing spatial dependency models for predicting type choice of new housing projects (Mohammadian et al. 2005), and so on. Such a modeling approach can account for both the group-specific heterogeneity (country-level) and individual observation-related heterogeneity within each of the groups.

Random parameter models are defined in terms of density of the observed random variable and the structural parameters of the model (Econometric Software Inc. 2016) as shown in Eq. 1.

Density of $y(i, t)=f[y(i, t), b(i), c(i), x(i, t)]$

Here, $b(i)$ and $c(i)$ are parameter vectors for each of the observations $i$, and $x(i, t)$ is a set of covariates observed at time $t$.

Random parameter models allow the coefficients of the predictors (for example, disaster impact factors and economic characteristics of the countries/regions) to vary across the observations per an analyst-specified continuous distribution (Anastasopoulos and Mannering 2011; Venkataraman et al. 2013; Mannering et al. 2016). A simulation-based maximum likelihood method is usually used to estimate the parameters of the random parameter models. The simulation procedure involves drawing the values of the parameters (coefficients of the predictors) from a given predefined distribution (Hasan et al. 2013). In this research, we assumed that the parameters follow a normal distribution, and these parameters of the statistically significant random variables are reported in terms of the mean and the standard deviation that describes the parameters' predefined distribution. Thus, the parameter estimates reported in the random parameter models are less influenced by the unobserved heterogeneities (Mannering et al. 2016).

The major reasons for leveraging the random parameter modeling technique in our research are summarized as follows:

1. Random parameter models allow the coefficients of predictors to vary across the countries/regions per an analyst-specified continuous distribution (such as the normal distribution in this case) (Anastasopoulos and 
Mannering 2011; Venkataraman et al. 2013; Mannering et al. 2016).

2. Random parameter models also perform well in describing the parameter heterogeneity (Mannering et al. 2016). This type of heterogeneity occurs when a single predictor variable (for example, disaster impact variable and economic characteristics of the countries/ regions) is forced to have the same effect on the response variable (country-level economic growth) through a fixed parameter. Thus, a random parameter model better explains the stochastic effects of the predictors on the response variable, reducing the related bias in the model estimation (Mannering et al. 2016).

3. Random parameter models can yield reasonably accurate results even when based on a less detailed dataset (Anastasopoulos and Mannering 2011).

Despite the advantages of the random parameter model, there are certain disadvantages associated with this approach. First, it is a parametric modeling approach, that is, estimation of a traditional random parameter model requires a parametric assumption (assumed distribution for the variation in parameters across observations). This is a strong assumption given that the factors attributed to the disaster impacts are likely to be skewed and multimodal in most of the cases. However, this disadvantage can be overcome by testing a variety of distributions that offers the best overall statistical fit. Second, the random parameter model works well under the assumption that there is no (time invariant) omitted variable bias.

\subsection{Model Construct}

Panel data or longitudinal data refers to a multidimensional dataset that observes series of cross-sectional data over time (Baltagi 2013). Figure 1 describes the multiple layers of data types that are considered in this research. Layer-1 (shaded in grey) depicts an individual country or region at a time, say year $=t_{1}$ (cross-sectional data). A cluster of Layer-1s signifies all the countries/regions (1 to $n$, where $n$ is the total number of countries/regions) in the world, and their characteristics observed at a time constitute a second layer, the layer of time (Layer-2). Sequentially placed Layer-2s describe the dimension of time in this research. Thus, for such a type of dataset, considering only the crosssectional features of data will lose information about time dynamics, whereas conducting only a time series analysis will overlook the country/region-level cross-sectional heterogeneities. This will lead to misinterpreting the information available from the dataset.

The empirical representation of a panel data model can be represented as shown in Eq. 2:
Growth $_{i, t}=\eta_{i}+\varphi_{t}+\delta_{i} t+\alpha_{i, t}$ Impact $_{i, t}$

$$
+\beta_{i, t} \text { EconFactors }_{i, t}+\varepsilon_{i, t}
$$

The variable Growth $_{i, t}$ is measured as a percentage change in real GDP (2005 constant dollars) per capita in a year $t$ for a particular country or region $i$ and is computed as follows (Eq. 3):

Growth $_{i, t}=\frac{\operatorname{rgdpl} 2_{i, t}-\operatorname{rgdpl} 2_{i, t-1}}{\operatorname{rgdpl} 2_{i, t-1}} * 100 \%$

Here, $\operatorname{rgdpl} 2_{i, t}$ refers to the real GDP (2005 constant dollars) per capita in a year $t$ for a particular country or region $i$ as mentioned in the Penn World Table (PWT version 7.1) (Heston et al. 2012); $\eta_{i}$ is the country/regionspecific fixed effects, $\varphi_{t}$ is the global time variant shock, and $\delta_{i} t$ is the country/region-specific time trend; $\alpha_{i, t}$ represents the coefficients of the disaster impact variables and $\beta_{i, t}$ captures the coefficients of the significant economic factors that influence the economic growth of a country or region; $\varepsilon_{i, t}$ is the error term that captures the effect of all the unobserved factors that influences the response variable, Growth ${ }_{i, t}$, in the model. The model estimation follows the "zero conditional mean" assumption, which states that for any given value of the independent variables (here, Impact $_{i, t}$ and EconFactors Ext $_{i, t}$ ), the expected value of the disturbance term $\varepsilon_{i, t}$ is the same in all the cases, and is equal to the value of $\epsilon$ for the entire population which is equal to zero. This implies that $E\left(\varepsilon_{i, t} \mid\right.$ Impact $_{i, t}$, EconFactors $\left._{i, t}\right)=E(\epsilon)=0 \quad$ (Wooldridge 2002).

The "fixed effects" component of the model includes unobserved heterogeneity that is present due to the unique nature of the different countries/regions such as location, economic health, governance, trading policies, and so on. The "time effect" component can be represented in terms of time trends that capture the unobserved heterogeneity persistent for all the countries/regions due to the prolonged time-period, such as, inflation, climate change, urbanization, and so forth. Many times, growth economists also use 5-10 year averages in their estimation process (Cavallo et al. 2010), but this process might lead to loss of information from the data and might lead to inadequate model estimation. In this research, Growth is measured as is given in Eq. 3 (Albala-Bertrand 1993). However, it should be noted that variables rgdpl and rgdplch (available in the PWT 7.0 dataset, also representing countries/regions' real GDP) can also be used for model estimation, and the results will be the same because they are just different methods of GDP estimation and are not significantly different from each other. Real GDP is considered in this research because it eliminates the effect of inflation over time. The basic ordinary least square model is given by Eq. 2 . 


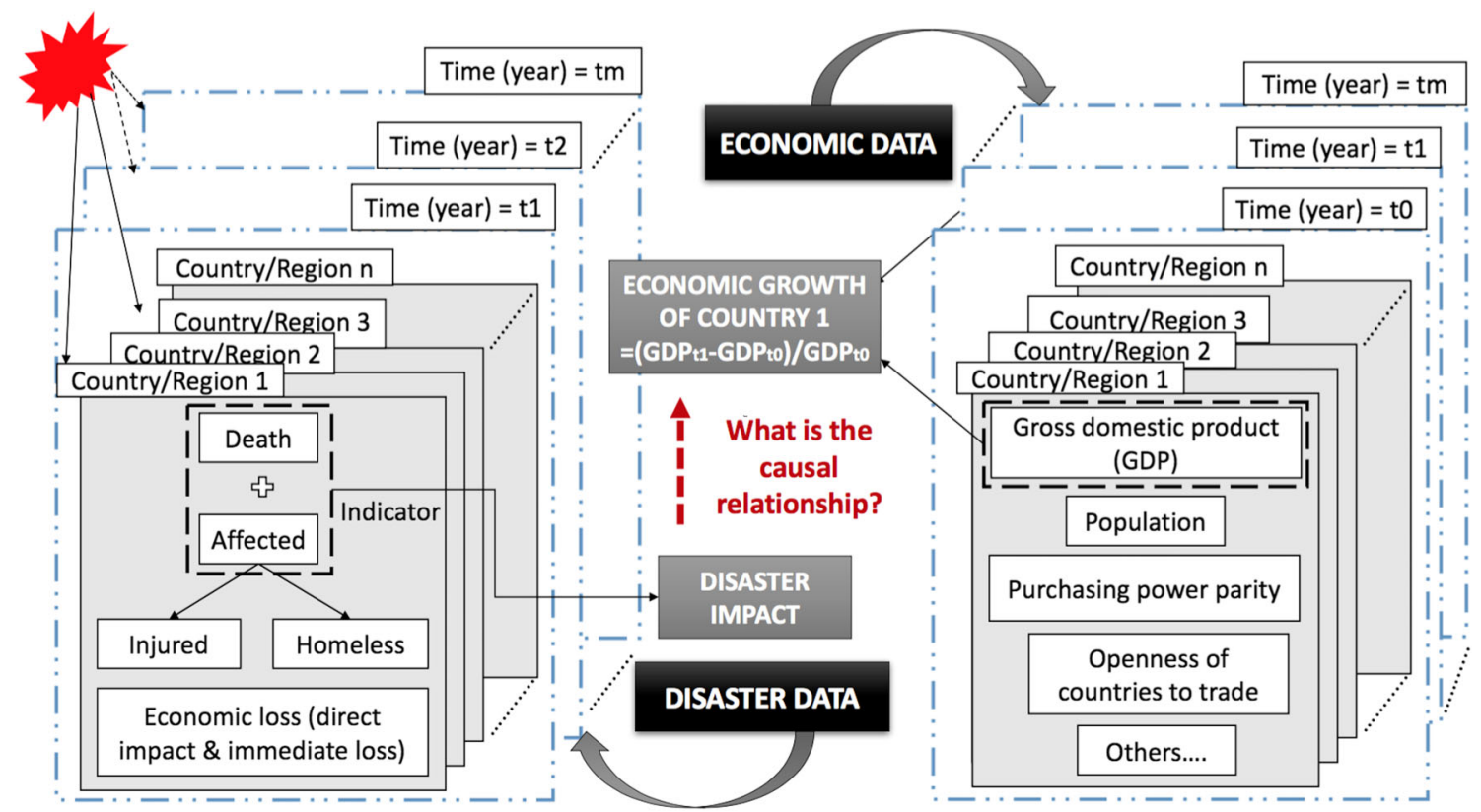

Fig. 1 Methodology and research construct. Source Mukherjee and Hastak (2016)

\subsection{Data Description}

Two types of datasets were used in this research: (1) economic data of the countries/regions including variables such as gross domestic product (GDP), population, purchasing power parity (PPP), and openness to trade obtained from the Penn World Tables (PWT version 7.1) (Heston et al. 2012); and (2) disaster data obtained from the EMDAT database maintained by CRED (Centre for Research on the Epidemiology of Disasters) (Guha-Sapir et al. 2015). The EM-DAT database records the impact of a disaster based on human dimensions, that is, the number of people who died or were affected or became homeless due to a disaster and direct economic damage, but does not consider the physical attributes of the disaster, that is, the magnitude of a seismic event on the Richter scale or the amount of rain recorded that caused a flood, and so on. The two datasets from different sources were combined using the "countries/regions" and "years" (from 1970 to 2010) as nexus (shown in Fig. 1). Thus, the final dataset used for analysis contained both the economic information and the corresponding disaster-related data over the years from 1970 to 2010. The two different sources for economic data and disaster data are described below.

Economic data The Penn World Tables (PWT) database provides data on national income accounts and purchasing power parity of 189 countries/regions over the years 19502010. It uses 2005 as the reference year and the real values of the economic variables are calculated using the 2005 constant dollar value. In this research, the real economic growth of a country or region in a year is treated as the response variable and is defined as the percentage increase of real GDP per capita per year. The benefit of using per capita real GDP is that it eliminates the component of GDP increase due to population increase and the effect of inflation over time. In this context, for the purpose of analysis, we chose to use the purchasing power parity (PPP) converted GDP per capita (Laspeyres), at 2005 constant prices (rgdpl2: symbol used in PWT table) (Heston et al. 2012) as a measure for annual GDP per capita in a country or region.

Disaster data Collecting, processing, and managing disaster data is one of the most challenging and cost-intensive tasks, and ensuring high quality of disaster data is extremely important for accurate results from the disaster data analysis (Guha-Sapir and Below 2002; Wirtz et al. 2014). Scientists, governmental and nongovernmental organizations, and the finance industry make use of the global databases that contain losses attributable to natural catastrophes. There are three global and multi-peril loss databases-NatCatSERVICE (Munich Re), Sigma (Swiss $\mathrm{Re})$, and the EM-DAT database developed and maintained by the Centre for Research on the Epidemiology of Disasters (CRED) (Guha-Sapir and Below 2002; Wirtz et al. 2014) — that are used for analyzing and understanding disaster impacts. For this research, we obtained the disaster data from the EM-DAT database. Data maintained by this system is collected after a country/region is impacted by a disaster. Thus, sometimes there is a time lapse between the actual occurrence of the disaster and the time when the data is collected, which might underestimate the actual disaster impact. However, since our research focused on analyzing 
the country/region-level disaster impacts on their economic growth, minor underestimations do not have significant impact on our model results. Of the three disaster databases mentioned above, EM-DAT is the only publicly available database that provides country/region-level disaster data (Guha-Sapir and Below 2002). This database has been successfully used in other studies for analyzing and understanding the effects of disasters (Skidmore and Toya 2002; Hoyois and Guha-Sapir 2003, 2005; Toya and Skidmore 2007; Hochrainer 2009; Gassebner et al. 2010).

A disaster event is recorded into the EM-DAT database system if it satisfies one of the following criteria: (1) 10 or more people are reported to have been killed; (2) 100 or more people are reported to have been affected, that is, either injured or have become homeless or affected in some other way; (3) there has been a call for international assistance; and (4) a state of emergency has been declared (Guha-Sapir et al. 2015). The number of fatalities and total people affected are considered proxy variables to measure the impact of a disaster event in this research. This methodology has been used in several other studies such as Kahn et al. (2005), Shabnam (2014), and Toya and Skidmore (2007). The distribution of various types of natural hazard-induced disasters with respect to their total number of occurrences during the period of analysis indicate that flood is the most frequently occurring disaster globally, followed by storms.

\subsection{Model Estimation Procedure}

The empirics of growth-econometrics is dependent on panel data techniques (Cavallo et al. 2010). These techniques account for both the fixed effects and time effects related to the observations. In this research, the observations from each country or region are considered as a single group to consider the fixed effects. The modeling approach accounts for the disaster impact in terms of the number of fatalities or the number of people affected (injured, homeless, or affected). The damage to infrastructure and housing due to a disaster is also considered to be a factor of disaster impact. If people became homeless in a post-disaster situation, it implies that the disaster destroyed housing and infrastructure, which affects the economy; thus, the number of people becoming homeless is considered as an indicator for housing damage in the model. Moreover, the effect of disaster on economic growth has long-term effects into the future. Depending on the extent of disasters and the amount of aid the countries/regions receive from the World Bank, the United Nations, and other organizations to build back and restore from the disaster, the subsequent years of a disaster might see a growth in the economy. This longterm effect of a disaster on economic growth is captured with lagged disaster impact variables.
Explanatory variables such as population of a country/ region, its trading behavior, real GDP per capita, and so on, are used as control variables to capture its economic characteristics. Since economic growth of a country or region is dependent on its economic health and economic behavior, it is very important to include these variables in the model (as they might significantly affect the growth in each year). This would help to eliminate the influence of other factors that influence the economic growth, other than natural hazard-induced disasters, thus providing unbiased estimates for the model results.

\section{Results and Discussion}

In this section, we present the results of the exploratory analysis on understanding the global distribution of disaster impacts, followed by model estimation results. We conclude this section by providing a discussion on the implication of our results. Our exploratory analysis provides valuable insights on how the extent of disaster impacts varies across the globe for different countries/regions based on their location, economy, and development.

\subsection{Exploratory Analysis Results}

We conducted an exploratory analysis of the country/region-level natural hazard-induced disaster impacts data across the globe to provide insights on the spatial distribution of the severity of the disasters. Intensity of disaster impacts as measured by fatalities per millions of populations, or the number of affected people per millions of populations vary widely across the world. While we observe a wide range of variations across different countries/regions, there is a distinct trend that shows economically poor and developing countries are affected more than the developed countries. The major reasons behind such variations are rooted in the risk tolerance and resilience of the countries/regions.

From our preliminary exploratory data analysis, we found that Bahrain is impacted the most, followed by Maldives, Ethiopia, and Sudan in terms of the average number of fatalities per millions of populations in a country/region. In terms of the total number of people affected per millions of populations in a country or region, Antigua and Barbuda ranks at the top, followed by Swaziland, Djibouti, and Belize. The gross national incomes (GNI) per capita of these countries are much lower, varying from 18,660 (Bahrain) to 341 (Ethiopia) in 2010 current USD, as compared to the United States with a GNI per capita of USD 48,950 as of 2010 (World Bank 2016a). Bahrain (USD 18,660 GNI per capita) and Antigua and Barbuda (USD 12,620 GNI per capita) fall in the high- 
income group, whereas all the other countries mentioned above fall in the middle-income or lower-income groups (World Bank 2016a).

Besides analyzing disaster severities in terms of fatalities and extent of affected population, analysis of the disaster frequencies also revealed interesting results in identifying the countries/regions that are more exposed to the various types of disasters. We found that among the top six countries in the world that have experienced disasters most frequently, India ranks first, followed by Indonesia, the United States, the Philippines, Bangladesh, and Mexico.

Figure 2 shows that during the 40-year span of 1970-2010, floods occurred $31.2 \%$ of the time and ranked as the topmost frequently occurring disaster. Storms occurred $20 \%$ of the time, and epidemics occurred $13.4 \%$ of the time during the same time-period.

\subsection{Model Estimation Results}

In this section, we present the summary statistics of the significant predictors as obtained from our model, followed by the model estimation results and inference. The descriptive statistics of the statistically significant variables, as predicted by the random parameter panel data model, are given in Table 1 .

Considering the estimation coefficients, the results of the model show that among all the different types of disasters, on average $55 \%$ of the time, flood related disasters have significantly impacted economic growth. This result is consistent with the fact that of all extreme events, floods represent $31.2 \%$ of the cumulative counts, highest among all types of disasters (Fig. 2). The results in Table 2 indicate that if there is a $10 \%$ increase in the number of affected people, the growth of a country/region on average will decrease by $0.0135 \%$ per capita as an immediate effect in that year. But, it is observed that after 3 years of a disaster occurrence, under ceteris paribus condition, the economic growth on average will increase by $0.0158 \%$.

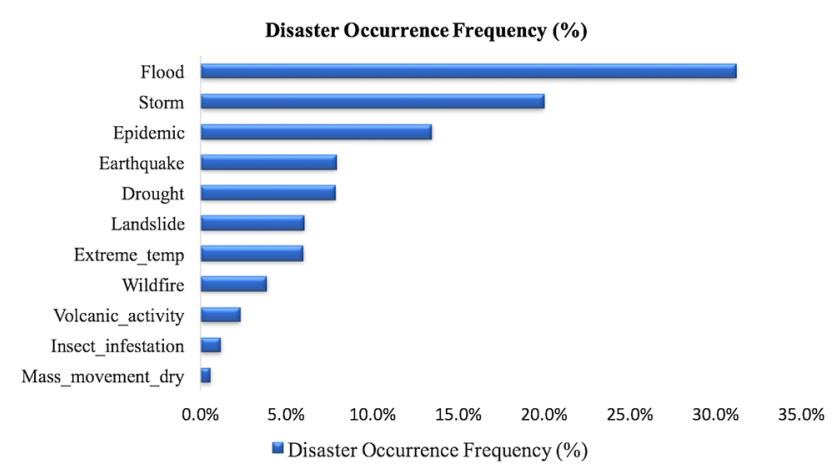

Fig. 2 Distribution of various types of disaster occurrences globally from 1970-2010
This is an interesting observation because based on the extent of a disaster impact, a country or region receives financial aid from other countries and organizations to rebuild the infrastructures and houses that creates more jobs and rebuilds the economy. Although this effect is very often observed for developing and poor countries, the "build back better after a disaster" concept is equally applicable in developed and developing countries/regions. We also observe that the extent of fatalities (intensity of a disaster) has a delayed effect on economic growth as compared to the less severe disaster impacts, represented by the extent of people affected/injured.

The estimation results of the model are shown in Table 2. The estimated parameter values and the t-statistics of the significant variables that indicate the disaster impact and economic characteristics of the countries/regions are also summarized. All the parameters identified are significantly different than zero at more than $90 \%$ confidence level. The overall fit of the model is given by Eq. 4:

$\rho^{2}=1-\frac{\log -\text { likelihood at convergence }}{\text { Restricted Log }- \text { likelihood at constant }}$

From Table 2, we also observe that the immediate effects of the extent of fatalities on economic growth are not statistically significant, but the lagged effects observed after 3 years of a disaster occurrence are found to be statistically significant. With a $10 \%$ increase in the fatality counts due to a disaster impact, there is a significant dip (on average by $0.0212 \%$ ) in the economic growth of a country or region after 3 years of the disaster impact. However, after the 4th year of the disaster, the economic growth increases by $0.0099 \%$ per capita as compared to, if the disaster had not occurred. This result contrasts with how the extent of people affected (that is, the number of people affected, injured, or homeless) influences the country/region-level economic growth in a post-disaster scenario. We reason such a pattern of impact as follows: although the severity of the incident that "people being affected" is less than that of the "extent of fatalities," the former is much more predominant and widespread under any type of disaster scenario than the latter, resulting in affecting the economy immediately. Moreover, the amount of financial aid allotted to a country or region in a postdisaster scenario mostly depends on the extent of people being affected to help them in the recovery process. This argument is also validated by another result obtained from our model. The model shows that if people become homeless after a disaster, it has a significant negative influence on the country/region-level economic growth. With a $100 \%$ increase in the number of people who become homeless, the economic growth decreases by $0.28 \%$ per capita on average. However, the results show that the effect of such a variable is significantly random, that is, it has 
Table 1 Descriptive statistics of statistically significant explanatory variables used in the model

\begin{tabular}{|c|c|c|c|c|}
\hline Variable name & Mean & SD & Min & Max \\
\hline Population (natural logarithm) & 8.48 & 2.06 & 2.50 & 14.10 \\
\hline $\begin{array}{l}\text { Direct impact of total number of affected, injured, and homeless people (natural logarithm) on } \\
\text { growth }\end{array}$ & 10.02 & 3.25 & 0.0 & 19.65 \\
\hline $\begin{array}{l}3 \text { years lagged effect of total number of affected, injured, and homeless people (natural logarithm) on } \\
\text { growth }\end{array}$ & 9.98 & 3.28 & 0.0 & 19.65 \\
\hline 3 years lagged effect of total number of fatalities (natural logarithm) on growth & 3.87 & 2.18 & 0.0 & 12.61 \\
\hline 4 years lagged effect of total number of fatalities (natural logarithm) on growth & 3.90 & 2.17 & 0.0 & 12.61 \\
\hline PPP converted GDP per capita (Laspeyres method) measured in 2005 constant international dollars & 9092.4 & $11,070.3$ & 160.8 & $98,024.2$ \\
\hline Indicator for if people became homeless after a disaster occurred & 0.16 & 0.37 & 0 & 1 \\
\hline Openness to trade for each of the countries/regions at 2005 constant prices (\%) & 73.24 & 46.38 & 1.16 & 433.05 \\
\hline Government consumption share of PPP converted GDP per capita at 2005 constant prices & 12.59 & 9.48 & 0.73 & 67.19 \\
\hline Investment share of PPP converted GDP per capita at 2005 constant prices & 23.14 & 11.30 & -11.5 & 93.64 \\
\hline Flood indicator & 0.55 & 0.50 & 0 & 1 \\
\hline Global economic recession period 2007-2010 indicator & 0.08 & 0.27 & 0 & 1 \\
\hline Global economic recession period $1980-1984$ indicator & 0.11 & 0.32 & 0 & 1 \\
\hline
\end{tabular}

statistically significant random parameter that varies from one country or region to another. This can be explained by the fact that countries/regions that receive governmental and nongovernmental help in the post-disaster period for recovery and restoration efforts might experience a growth in their economy while those who do not receive such help experience a decline in their economic growth.

The model results also show that if a country has $10 \%$ higher population than another economically comparable country, then its economic growth will increase by $0.0617 \%$ on average, when all other factors are constant (ceteris paribus condition). The model results also show that if a country or region is wealthier than its present situation at the time of a future disaster scenario, it will be impacted more than what it experienced before, under the ceteris paribus condition. Statistically, the results from the model can be explained as: if the real GDP of a country/ region is 1000 international dollars per capita more than what it had, it will experience a decrease in economic growth by $0.051 \%$, under the ceteris paribus condition. International dollar is a term mostly used in economics in conjunction with a country's purchasing power parity and is defined by the World Bank as: "an international dollar would buy in the cited country a comparable amount of goods and services a U.S. dollar would buy in the United States" (World Bank 2016b). This is a reasonable outcome because the countries/regions with higher GDP (economically wealthier) will encounter more economic losses as they lose more of their valuable infrastructures and properties, leading to higher physical and economic losses (due to losses in business) thus, it also takes more time to recover back to the normal situation after being impacted by a disaster. Other economic characteristics such as the trading behavior indicated by the openness of the countries/ regions to trade, the government share of purchasing power parity (PPP) converted gross domestic product (GDP) per capita, and the investment share of PPP converted GDP per capita are also found to be statistically significant. Countries/regions with higher values of such economic attributes are found to be less affected under the influence of a similar intensity disaster. The countries/regions with higher openness to trade, higher government share in GDP, and higher investment share in GDP, will experience growth in their economies even in a post-disaster scenario. However, openness to trade and government consumption share are found to be statistically significant with statistically significant random parameters, that is, the effects of these two variables are different for different countries/regions. The ordinary fixed effects panel data model cannot capture this country/region-specific randomness of such variables and, thus, would leave many unobserved heterogeneities in the error terms, which would render biased estimates of the parameters. Thus, a random parameter panel data model is a better model choice over the traditionally used fixedeffects or random-effects panel data models.

After the model was constructed, the temporal effect of the model with respect to different time periods was investigated using the log-likelihood ratio test. The sample data was divided into two sub-samples-one from 1970-1989 and the other from 1990-2010. The sample models were estimated for each of these two time-periods using the same statistically significant variables as obtained 
Table 2 Random parameter panel data model to estimate the impact of natural hazard-induced disasters on country/region-level economic growth (SD of the significant random parameters are given in parentheses)

\begin{tabular}{|c|c|c|}
\hline Variable description & Estimates & t-Stat \\
\hline Constant & -6.968 & -4.78 \\
\hline $\begin{array}{l}\text { Indicator variable for global economic recession period } 2007-2010 \text { ( } 1 \text { - if observations } \\
\text { are from the time period } 2007-2010,0 \text { - if otherwise) }\end{array}$ & -1.419 & -2.77 \\
\hline $\begin{array}{l}\text { Indicator variable for global Economic recession period } 1980-1984 \text { indicator ( } 1 \text { - if } \\
\text { observations are from the time period } 1980-1984,0 \text { - if otherwise) }\end{array}$ & -1.769 & -2.73 \\
\hline Flood indicator variable ( $1-$ if the disaster event is flood, 0 - if otherwise) & 0.903 & 0.03 \\
\hline \multicolumn{3}{|l|}{ Disaster impact } \\
\hline $\begin{array}{l}\text { Direct impact of the total number of affected, injured, and homeless people (natural } \\
\text { logarithm) on country/region-level economic growth }\end{array}$ & -0.135 & -1.78 \\
\hline $\begin{array}{l}3 \text { years lagged effect of the total number of affected, injured, and homeless people } \\
\text { (natural logarithm) on country/region-level economic growth }\end{array}$ & 0.158 & 1.73 \\
\hline $\begin{array}{l}3 \text { years lagged effect of the total number of fatalities (natural logarithm) on country/ } \\
\text { region-level economic growth }\end{array}$ & -0.212 & -2.09 \\
\hline $\begin{array}{l}4 \text { years lagged effect of the total number of fatalities (natural logarithm) on country/ } \\
\text { region-level economic growth }\end{array}$ & $0.099(0.149)$ & $1.24(5.01)$ \\
\hline Indicator for if people became homeless after a disaster occurred & $-0.280(0.552)$ & $-0.86(2.76)$ \\
\hline \multicolumn{3}{|l|}{ Economic characteristics of the countries/regions } \\
\hline Population (natural logarithm) & 0.617 & 3.50 \\
\hline $\begin{array}{l}\text { PPP converted GDP per capita (Laspeyres method) measured in } 2005 \text { constant } \\
\text { international dollars }\end{array}$ & $-0.51 \times 10^{-4}$ & -2.37 \\
\hline Openness to trade for each of the countries/regions at 2005 constant prices (\%) & $0.015(0.007)$ & $3.06(3.36)$ \\
\hline $\begin{array}{l}\text { Government consumption share of PPP converted GDP per capita at } 2005 \text { constant } \\
\text { prices }\end{array}$ & $0.34 \times 10^{-4}(0.085)$ & $0.001(6.58)$ \\
\hline Investment share of PPP converted GDP per capita at 2005 constant prices & 0.125 & 6.94 \\
\hline Number of observations & 1131 & \\
\hline Log-likelihood at convergence & -3282.74 & \\
\hline Restricted log-likelihood at zero & -3448.94 & \\
\hline$\rho^{2}$ & 0.0482 & \\
\hline
\end{tabular}

from the full sample model, and the test statistic for the log-likelihood ratio test was calculated using Eq. 5:

$-2\left[\operatorname{LL}\left(\beta_{1970-2010}\right)-\operatorname{LL}\left(\beta_{1970-1989}\right)-\operatorname{LL}\left(\beta_{1990-2010}\right)\right]$

Here, $\operatorname{LL}\left(\beta_{1970-2010}\right)$ is the log-likelihood at convergence for the full sample model, $\operatorname{LL}\left(\beta_{1970-1989}\right)$ is the log-likelihood at convergence for the sample data from 1970-1989 and $\operatorname{LL}\left(\beta_{1990-2010}\right)$ is the log-likelihood at convergence for the sample data from 1990-2010. The test statistic was found to be $49.8774>\chi_{\text {cri }}^{2}$ for 17 degrees of freedom. Therefore, the null hypothesis that the model had temporal stability over time was rejected at $99 \%$ confidence level. To include these time effects, indicator variables were constructed mostly for the five major economic depression periods-1974-1975, 1980-1984, 1991-1993, 2001-2002, and 2007-2010 (Tapia 2013). The economic recession of 1980-1984 and the great global recession of 2007-2010 were found to be statistically significant in causing a negative impact on the growth of the countries/regions, as can be observed from Table 2. Due to the economic recession in 1980-1984, country/region level economic growth on average was reduced by $1.768 \%$, and during the great recession of 2007-2010, the country/region level economic growth decreased by $1.42 \%$ on average under the ceteris paribus condition.

\section{Research Limitations}

We have presented a novel methodological framework to assess the impact of natural hazard-induced disasters on the economic growth of countries/regions around the world. We used the EM-DAT database developed and maintained by the Centre for Research on the Epidemiology of Disasters to obtain information about disasters from 1970 to 2010. However, there are some limitations associated with this database. The major limitation mostly arises from the measurement errors and the bias associated with the expost measurements. Data collected for the EMDAT 
database are recorded in the post-disaster period, when the intensity of such impacts might have significantly changed over time. However, with the recent advancements in data collection technologies in the disaster research field, the quality of the disaster data being collected has also improved. The CES ifo Group, consisting of the Center for Economic Studies (CES), the ifo Institute, and the CES ifo $\mathrm{GmbH}$ (Munich Society for the Promotion of Economic Research) has developed a country/region-level database that provides the intensity of the various disasters that have occurred in the past and can accommodate the ex-post nature of the disaster data to a certain extent (CES ifo Munich Group 2017). In the future, this database can also be integrated with our existing analysis to further enhance the accuracy of our model results.

\section{Conclusion}

Natural hazard-induced disasters affect economic growth of countries/regions, but the effect varies over time. In the beginning, country/region-level economic growth decreases after a disaster strikes, and then economic growth increases again. Economic recession periods also negatively influence economic growth and are captured in the model by considering different time periods. Economic characteristics are also considered in the model to control for their effects on growth.

The relationship between natural hazard-induced disasters and economic growth is highly complex and understanding of this relationship is still in a developing phase. The presence of several unobserved heterogeneities that affect the growth of a country or region makes assessing the relationships between disaster impact and economic growth difficult. This research combined economic and disaster datasets for the various countries/regions over the world and conducted a panel data analysis to develop a growth impact model. The hybrid modeling technique of panel data analysis with random parameters considered different types of heterogeneities that could be present in a panel dataset, such as, country/region-specific heterogeneity and time trends, and global time trends. However, a more severe problem exists when analyzing such disasterrelated data because there is always a lack of information and/or data available describing such disasters is inaccurate and of poor quality; thus, the types of predictor variables available are not exhaustive. This leads to a biased estimation of the coefficients resulting from the unobserved heterogeneities arising from omitted variables. In our research, such omitted variable bias might arise from the fact that the predictor variables describing the impact of natural hazard-induced disasters cannot completely explain the variation in economic growth of the different countries/ regions. It is noteworthy that although the random parameter model does address parameter heterogeneity, it does not consider the omitted variable bias that could lead to biased estimates of the coefficients. In such a scenario, when omitted variable bias may be a problem, other methods such as the fixed effects models would be more suitable for implementation.

In this research, all the disaster types are considered, to obtain an overall understanding of the disaster impact and growth econometrics. However, further research needs to be conducted in this area to understand what type of disaster affects economic growth the most, and this would help in developing and planning specific mitigation efforts at the country/region level. In infrastructure management research, the macroeconomic perspective of the disaster impact is not explored. Growth econometric models can combine the disaster-related problems that directly impact the economy of a country or region and are, thus, able to fill the gaps in the body of knowledge. Moreover, since econometric models are data-driven, results obtained from these models are reliable and an accurate interpretation of such results will help in policy and decision making in the field of disaster risk management.

Open Access This article is distributed under the terms of the Creative Commons Attribution 4.0 International License (http://crea tivecommons.org/licenses/by/4.0/), which permits unrestricted use, distribution, and reproduction in any medium, provided you give appropriate credit to the original author(s) and the source, provide a link to the Creative Commons license, and indicate if changes were made.

\section{References}

Aisen, A, and F.J. Veiga. 2013. How does political instability affect economic growth? European Journal of Political Economy 29(C): 151-167.

Albala-Bertrand, J.M. 1993. Natural disaster situations and growth: A macroeconomic model for sudden disaster impacts. World Development 21(9): 1417-1434.

Anastasopoulos, P.Ch., and F.L. Mannering. 2009. A note on modeling vehicle accident frequencies with random-parameters count models. Accident Analysis \& Prevention 41(1): 153-159.

Anastasopoulos, P.Ch., and F.L. Mannering. 2011. An empirical assessment of fixed and random parameter logit models using crash- and non-crash-specific injury data. Accident Analysis and Prevention 43(3): 1140-1147.

Baltagi, B.H. 2013. Econometric analysis of panel data, 5th edn. Hoboken: Wiley.

Cadwalladr, C. 2015. Nepal earthquake: The village wiped off the map in a few terrifying seconds. The Guardian, 17 May 2015. https://www.theguardian.com/world/2015/may/17/nepal-earth quake-langtang-village-everyone-was-dead. Accessed 20 Nov 2017.

Carlsson, F., and P. Martinsson. 2007. Willingness to pay among Swedish households to avoid power outages: A random parameter Tobit model approach. The Energy Journal 28(1): 75-89. 
Cavallo, E., S. Galiani, I. Noy, and J. Pantano. 2010. Catatrophic natural disasters and economic growth. Inter-American Development Bank working paper series No. IDB-WP-183. http:// www.iadb.org/res/publications/pubfiles/pubidb-wp-183.pdf. Accessed 5 Dec 2017.

CES (Center for Economic Studies) ifo Munich Group. 2017. Ifo GAME-The geological and meteorological events database. https://www.cesifo-group.de/ifoHome/research/Departments/ International-Trade/Ifo_GAME.html. Accessed 20 Sept 2017.

Cunado, J., and S. Ferreira. 2011. The macroeconomic impacts of natural disasters: New evidence from floods. Paper prepared for Agricultural and Applied Economics Association's 2011 AAEA \& NAREA Joint Annual Meeting, Pittsburgh, Pennsylvania, 2426 July 2011.

Dinu, R.R., and A. Veeraragavan. 2011. Random parameter models for accident prediction on two-lane undivided highways in India. Journal of Safety Research 42(1): 39-42.

Dowrick, S., and M. Rogers. 2002. Classical and technological convergence: Beyond the Solow-Swan growth model. Oxford Economic Papers 54(3): 369-385.

Econometric Software Inc. 2016. Panel data models: Random parameters-mixed models. http://www.limdep.com/features/ capabilities/panel_data/random_parameters_multilevel_6.php. Accessed 1 Jan 2016.

Gassebner, M., A. Keck, and R. Teh. 2010. Shaken, not stirred: The impact of disasters on international trade. Review of International Economics 18(2): 351-368.

Guha-Sapir, D., and R. Below. 2002. The quality and accuracy of disaster data: A comparative analysis of three global data sets. The Disaster Management Facility, The World Bank, Working Paper No. 191. http://www.cred.be/sites/default/files/Quality_ accuracy_disaster_data.pdf. Accessed 5 Dec 2017.

Guha-Sapir, D., R. Below, and Ph. Hoyois. 2015. EM-DAT: International disaster database. Brussels: Centre for Research on the Epidemiology of Disasters (CRED), Catholique University of Louvain.

Hasan, S., R. Mesa-Arango, and S. Ukkusuri. 2013. A randomparameter hazard-based model to understand household evacuation timing behavior. Transportation Research Part C: Emerging Technologies 27: 108-116.

Headey, D.D., and A. Hodge. 2009. The effect of population growth on economic growth: A meta-regression analysis of the macroeconomic literature. Population and Development Review 35(2): 221-248.

Heston, A., R. Summers, and B. Aten. 2012. Penn world table version 7.1, Center for International Comparisons of Production, Income and Prices at the University of Pennsylvania. https://pwt.sas. upenn.edu/php_site/pwt_index.php. Accessed 20 Sept 2017.

Hochrainer, S. 2009. Assessing the macroeconomic impacts of natural disasters: Are there any? Policy research working paper, No. WPS 4968. The World Bank. https://openknowledge.worldbank. org/handle/10986/4162 License: CC BY 3.0 IGO. Accessed 20 Nov 2017.

Hoyois, P., and D. Guha-Sapir. 2003. Three decades of floods in Europe: A preliminary analysis of EMDAT data. Brussels: Centre for Research on the Epidemiology of Disasters (CRED), Catholique University of Louvain.

Hoyois, P., and D. Guha-Sapir. 2005. Flood disasters in Europe: A short analysis of EMDAT data for years 1985-2004. Brussels: Centre for Research on the Epidemiology of Disasters (CRED), Catholique University of Louvain.

Jong-A-Pin, R. 2009. On the measurement of political instability and its impact on economic growth. European Journal of Political Economy 25(1): 15-29.

Kahn, M.E., D. Costa, S. Gerking, E. Glaeser, A. Levinson, J. Shapiro, J. Shimshack, and C. Timmins. 2005. The death toll from natural disasters: The role of income, geography, and institutions. The Review of Economics and Statistics 87(2): 271-284.

Katz, M. 2013. Hurricane Sandy flood damage-Toxic mold invading NYC homes and businesses. ReleaseWire, 31 January 2013. http://www.releasewire.com/press-releases/hurricane-sandyflood-damage-toxic-mold-invading-nyc-homes-and-businesses200065.htm. Accessed 20 Nov 2017.

Kousky, C. 2012. Informing climate adaptation: A review of the economic costs of natural disasters, their determinants, and risk reduction and options. Resources for the Future. Discussion Paper.

Mannering, F.L., V. Shankar, and C.R. Bhat. 2016. Unobserved heterogeneity and the statistical analysis of highway accident data. Analytic Methods in Accident Research 11(Supplement C): $1-16$.

Mohammadian, A., M. Haider, and P.S. Kanaroglou. 2005. Incorporating spatial dependencies in random parameter discrete choice models. Paper prepared for the 84th Annual Meeting of the Transportation Research Board, Washington, DC, January 2005. http://milute.mcgill.ca/Research/Senior/Spatial-MixedTRB_rev.pdf. Accessed 5 Dec 2017.

Momota, A. 2009. A population-macroeconomic growth model for currently developing countries. Journal of Economic Dynamics and Control 33(2): 431-453.

Mukherjee, S. 2017. Towards a resilient grid: A risk-based decision analysis incorporating the impacts of severe weather-induced power outages. Ph.D. dissertation, Purdue University, West Lafayette, Indiana, USA. https://www.researchgate.net/publica tion/321528706_Towards_a_resilient_grid_A_risk-based_deci sion_analysis_incorporating_the_impacts_of_severe_weatherinduced_power_outages. Accessed 5 Dec 2017.

Mukherjee, S., and M. Hastak. 2016. Risk of natural disasters on economic growth of a country: A random parameter panel-data analysis. Paper prepared for the 12th International Conference of the International Institute for Infrastructure Resilience and Reconstruction, University of Peradeniya, Kandy, Sri Lanka, 5-7 August 2016, 29-37. https://www.researchgate.net/publication/ 306548252. Accessed 20 Nov 2017.

Mukherjee, S., and R. Nateghi. 2017a. Climate, weather, socioeconomic and electricity usage data for the residential and commercial sectors in FL, U.S. Data in Brief 13: 192-195.

Mukherjee, S., and R. Nateghi. 2017b. Climate sensitivity of end-use electricity consumption in the built environment: An application to the state of Florida, United States. Energy 128: 688-700.

Mukherjee, S., and R. Nateghi. 2017c. Estimating climate-demand nexus to support long-term adequacy planning in the energy sector. In 2017 IEEE PES General Meeting, Chicago, 16-20 July 2017, IEEE Xplore. https://www.researchgate.net/publica tion/319851722. Accessed 20 Nov 2017.

Munich RE. 2012. Review of natural catastrophes in 2011: Earthquakes result in record loss year. Press Release. https://www. munichre.com/en/media-relations/publications/press-releases/ 2012/2012-01-04-press-release/index.html. Accessed 20 Nov 2017.

NASA (National Aeronautics and Space Administration). 2016. Fort McMurray wildfire continues to burn. Fire and Smoke. 9 May 2016. https://www.nasa.gov/feature/goddard/2016/fort-mcmur ray-wildfire-continues-to-burn. Accessed 9 Dec 2016.

Nateghi, R., and S. Mukherjee. 2017. A multi-paradigm framework to assess the impacts of climate change on end-use energy demand. PloS One 12(11). doi:https://doi.org/10.1371/journal.pone. 0188033.

Noy, I. 2009. The macroeconomic consequences of disasters. Journal of Development Economics 88(2): 221-231. 
Noy, I., and W. DuPont. 2017. Long-term consequences of natural disasters. Oxford research encyclopedia of natural hazard science. http://hdl.handle.net/10063/4981. Accessed 20 Nov 2017.

Plyer, A. 2016. Facts for features: Katrina impact. The Data Center. http://www.datacenterresearch.org/data-resources/katrina/factsfor-impact/. Accessed 30 Dec 2016.

Qayyum, U., and A. Haider. 2012. Foreign aid, external debt and economic growth nexus in low-income countries: The role of institutional quality. The Pakistan Development Review 51(4): 97-116.

Riebeek, H. 2005. The rising cost of natural disasters. Earth Observatory NASA. http://earthobservatory.nasa.gov/Features/ RisingCost/rising_cost5.php. Accessed 12 Nov 2014.

Sadia, B., M. Faheem, M. Nawaz, and K. Khan. 2012. Impact of disaster related mortality on gross domestic product: A case study of Pakistan. International Journal of Economics and Management 6(1): 128-149.

Shabnam, N. 2014. Natural disasters and economic growth: A review. International Journal of Disaster Risk Science 5(2): 157-163.

Skidmore, M., and H. Toya. 2002. Do natural disasters promote longrun growth? Economic Inquiry 40(4): 664-687.

Tang, C.F., and S. Abosedra. 2014. The impacts of tourism, energy consumption and political instability on economic growth in the MENA countries. Energy Policy 68: 458-464.

Tapia, J. 2013. From the oil crisis to the great recession: Five crises of the world economy. https://marxismocritico.com/2013/05/08/ from-the-oil-crisis-to-the-great-recession-five-crises-of-theworld-economy/. Accessed 20 Nov 2017.

Toya, H., and M. Skidmore. 2007. Economic development and the impacts of natural disasters. Economics Letters 94: 20-25.

Tumusiime, E., B.B. Wade, J. Mosali, J. Johnson, J. Locke, and J.T. Biermacher. 2011. Determining optimal levels of nitrogen fertilizer using random parameter models. Journal of Agricultural and Applied Economics 43(4): 541-552.

Venkataraman, N., G.F. Ulfarsson, and V.N. Shankar. 2013. Random parameter models of interstate crash frequencies by severity, number of vehicles involved, collision and location type. Accident Analysis \& Prevention 59: 309-318.

Wirtz, A., W. Kron, P. Löw, and M. Steuer. 2014. The need for data: Natural disasters and the challenges of database management. Natural Hazards 70(1): 135-157.

Wooldridge, J.M. 2002. Introductory economics: A modern approach, 2nd edn. Mason, OH: South-Western.

World Bank. 2016a. GNI per capita, atlas method (current US\$). World Bank national accounts data, and OECD national accounts data files. http://data.worldbank.org/indicator/NY. GNP.PCAP.CD? contextual $=$ default\&end $=2010$ \&locations $=X L-$ ET-SD-BH-MV-US-AG-SZ-BZ-DJ\&start=1987\&view=chart. Accessed 28 Nov 2017.

World Bank. 2016b. What is an "international dollar"? Currencies. https://datahelpdesk.worldbank.org/knowledgebase/articles/ 114944-what-is-an-international-dollar. Accessed 20 Nov 2017. 